\title{
Comparative maternal outcomes of oral nifedipine and intravenous labetalol for severe hypertension during pregnancy: an open label randomized controlled trial
}

\author{
Monika Kumari $^{1}$, Sita Thakur ${ }^{1}$, Kamal Singh ${ }^{1}$, Shashank Shekhar ${ }^{2 *}$
}

\begin{abstract}
${ }^{1}$ Department of Obstetrics and Gynecology, RKGMC, Hamirpur, Himachal Pradesh, India
${ }^{2}$ Department of Obstetrics and Gynecology, AIIMS, Jodhpur, Rajasthan, India
\end{abstract}

Received: 23 April 2020

Accepted: 29 May 2020

\section{*Correspondence:}

Dr. Shashank Shekhar,

E-mail: longshanks28@gmail.com

Copyright: (c) the author(s), publisher and licensee Medip Academy. This is an open-access article distributed under the terms of the Creative Commons Attribution Non-Commercial License, which permits unrestricted non-commercial use, distribution, and reproduction in any medium, provided the original work is properly cited.

\begin{abstract}
Background: Hypertensive diseases are commonly seen during pregnancy and remain one of the leading causes of maternal morbidity and mortality. Mostly commonly preferred drugs by health care providers for treatment of severe hypertension during pregnancy are labetalol and hydralazine. However, they require proper storage, intravenous access, and adequately trained staff for usage. Oral nifedipine in contrast is easier to use and widely available. Objective of this study was to report the efficacy and safety of oral nifedipine as compared to intravenous labetalol for treatment of severe hypertension during pregnancy.

Methods: It was an open label randomized controlled trial in which 100 women with severe hypertension during pregnancy were enrolled. They were randomized to receive either incremental doses of intravenous labetalol every 20 minutes (total $300 \mathrm{mg}$ ) or $10 \mathrm{mg}$ oral nifedipine every 20 minutes (up to $50 \mathrm{mg}$ ) to lower the blood pressure to safer levels.

Results: Women receiving oral nifedipine took significantly less time to achieve target blood pressure [(37.6 \pm 23.3$)$ minutes (SD) as compared to those receiving intravenous labetalol (52.0 minutes \pm 27.95 (SD)]. Women receiving nifedipine for treatment also required significantly lesser doses to control the blood pressure [mean dose 1.8 \pm 1.1 (SD) versus 2.6 $\pm 1.2(\mathrm{SD}) \mathrm{p}=0.006$ ]. There were two failures in labetalol group and one failure in nifedipine group. No serious adverse events were reported in either group.

Conclusions: Oral nifedipine is equally efficacious to I.V. labetalol for treatment of severe hypertension during pregnancy and is easier to use in low resource settings.
\end{abstract}

Keywords: Hypertensive disorders, Oral nifedipine, Severe hypertension during pregnancy, Severe pre-eclampsia

\section{INTRODUCTION}

Hypertension is one of the most common medical disorder during pregnancy affecting nearly one in ten pregnant women. Hypertensive disorders during pregnancy include gestational hypertension, preeclampsia, eclampsia and pre-existing hypertension with or without superimposed pre-eclampsia. ${ }^{1}$ A 2013 WHO international hospital survey on maternal and neonatal health found an incidence of pre-eclampsia of $2.5 \%$ and an incidence of eclampsia of $0.3 \%$ in 314623 women from Asia, Africa, and Latin America. ${ }^{2}$ Blood pressure may rise dangerously high in any of these disorders which poses serious threat of end-organ damage thus jeopardising maternal and fetal well-being. There is universal agreement to urgently treat acute severe hypertension during pregnancy however, there is no consensus regarding the choice of drug. ${ }^{3}$ Most popular and preferred drugs are intravenous hydralazine and labetalol among care givers especially in well developed 
countries. $^{4}$ Intravenous drugs need proper storage and adequately trained care givers for intravenous access, administration and monitoring. In contrast an oral drug is optimal with regard to usage and storage. Oral nifedipine has recently emerged as an alternative choice owing to publication of some good quality evidence attesting to its efficacy and safety. ${ }^{5,6}$ However, nifedipine is not listed in WHO essential list of drugs for treating severe hypertension during pregnancy. Further efforts to generate comparative evidence of efficacy and safety of oral drugs are required. Authors therefore conducted this study to compare the efficacy and safety of oral nifedipine and intravenous labetalol when given to treat severe hypertension during pregnancy.

\section{METHODS}

This open label randomized controlled trial was conducted in the department of obstetrics and gynecology of a tertiary care teaching institute. The study was approved by the institutional ethics committee. Pregnant women aged 18 years to 40 years at a gestation of 28 weeks or higher with severe hypertension as defined by systolic blood pressure (SBP) of $160 \mathrm{~mm}$ of mercury or higher and or diastolic blood pressure (DBP) of 110 or higher (measured on two occasions 15 minutes apart with women in a sitting position and arm cuff at the level of heart and disappearance of Korotkoff's sound as indicative of diastolic blood pressure) were approached for inclusion into the trial. Women who had taken antihypertensive drug in preceding 24 hours, who had structural or rhythm disorders of heart, heart failure, asthma or those not in a position to swallow tablets were ineligible. All enrolled women provided written informed consent. Randomization was done by a computergenerated randomization sequence (with an intention of 1:1 ratio) which was placed in an opaque sealed envelope. One hundred and nineteen women were approached, 19 women were excluded as they were not eligible. Target blood pressure was defined as SBP of 150 $\mathrm{mmHg}$ or lower and DBP of $100 \mathrm{mmHg}$ or lower (with both target BP values achieved). Women were divided into two groups. Group one received intravenous labetalol $20 \mathrm{mg}$ slowly over two to three minutes. Blood pressure was measured every 20 minutes till the target BP was achieved by further doses of $40 \mathrm{mg}, 80 \mathrm{mg}, 80 \mathrm{mg}$ and $80 \mathrm{mg}$ (total $300 \mathrm{mg}$ ). If target blood pressure was not achieved with maximum dose of labetalol then cross over to nifedipine was done. Women in second group received $10 \mathrm{mg}$ tablet of nifedipine every 20 minutes till the target BP was achieved or till the administration of maximum dose of $50 \mathrm{mg}$. Cross over to labetalol was done if maximum dose failed to achieve target blood pressure. Magnesium sulphate was administered to participants with severe pre-eclampsia as per hospital protocols. Participant data, including demographic characteristics, medical and pregnancy history, and labour course and labour outcomes, were collected. Aspartate transaminase, platelet count, serum creatinine concentration was measured at baseline. During the course of treatment continuous electronic fetal heart monitoring was done. In the event of non-reassuring fetal or maternal status for whatsoever reason the trial was to be abandoned and appropriate measures were taken. After the successful control of blood pressure, further antihypertensive therapy was started 2 hours after the last trial medication as per standard guidelines for the treatment of severe hypertension in pregnancy. Authors interviewed women after the study, after they were stable. They were asked about their experience with the trial and side-effects.

The primary outcome measured was the time needed to achieve target blood pressures. Secondary outcome included total number of antihypertensive dosages required to achieve the target $\mathrm{BP}$, maternal heart rate profile during the first 80 minutes, maternal hypotension (BP less than 90/60 mmHg), side effects profile, and perinatal outcomes. The perinatal outcomes of this study have already been reported earlier. ${ }^{7}$

\section{Statistical analysis}

A convenient sample size of 100 was chosen. The Statistical analyses were performed with the SPSS version 23.0 software package for windows (SPSS Inc., Chicago, IL, USA). Analysis was based on intention-totreat. One-sample Kolmogorov-Smirnov test was used to check normal distribution of continuous data. Student $t$ test was used to analyze normally distributed data and ordinal data were analyzed by Mann-Whitney $U$ test. Categorical data sets were analyzed with Fisher exact test. Repeated measure analysis of the variance was applied to the repeated measurements of BP and heart rate. All tests were two-sided and $\mathrm{p}$ value of $<0.05$ was considered significant.

\section{RESULTS}

Figure 1 shows the consolidated standards of reporting trials flow chart of the participants after enrolment. One hundred women were enrolled into the study, and 48 were randomized to receive intravenous labetalol and 52 women were randomised to receive oral nifedipine. As shown in the Table 1, two groups were similar with respect to maternal age, gravidity, parity, period of gestation at enrolment, period of gestation at delivery, incidence of preeclampsia, use of antenatal steroids, and the use of prophylactic magnesium sulphate. The initial mean systolic BP and diastolic BP were lower in the nifedipine group, although the difference was not statistically significant. Both groups had similar proportion of women with high systolic BP or diastolic $\mathrm{BP}$ alone. The mean time needed to achieve the target BP in women receiving nifedipine was $37.6 \pm 23.3$ minutes (SD) as compared with the mean time of 52.0 minutes \pm 27.95 (SD) for those receiving intravenous labetalol, as shown in Table 2. The nifedipine group required significantly fewer doses to achieve the target $\mathrm{BP}$ as compared with the labetalol group (mean dose 
$1.8 \pm 1.1(\mathrm{SD})$ mean dose $2.6 \pm 1.2(\mathrm{SD} \mathrm{p}=0.006)$. Target $\mathrm{BP}$ was not achieved in two women $(4.1 \%)$ randomized to labetalol compared with one woman in the nifedipine group $(1.9 \%)$. The group-wise (nifedipine and labetalol) systolic BP and diastolic BP profiles for the first 80 minutes at 20-minute interval are shown in Figure 2.

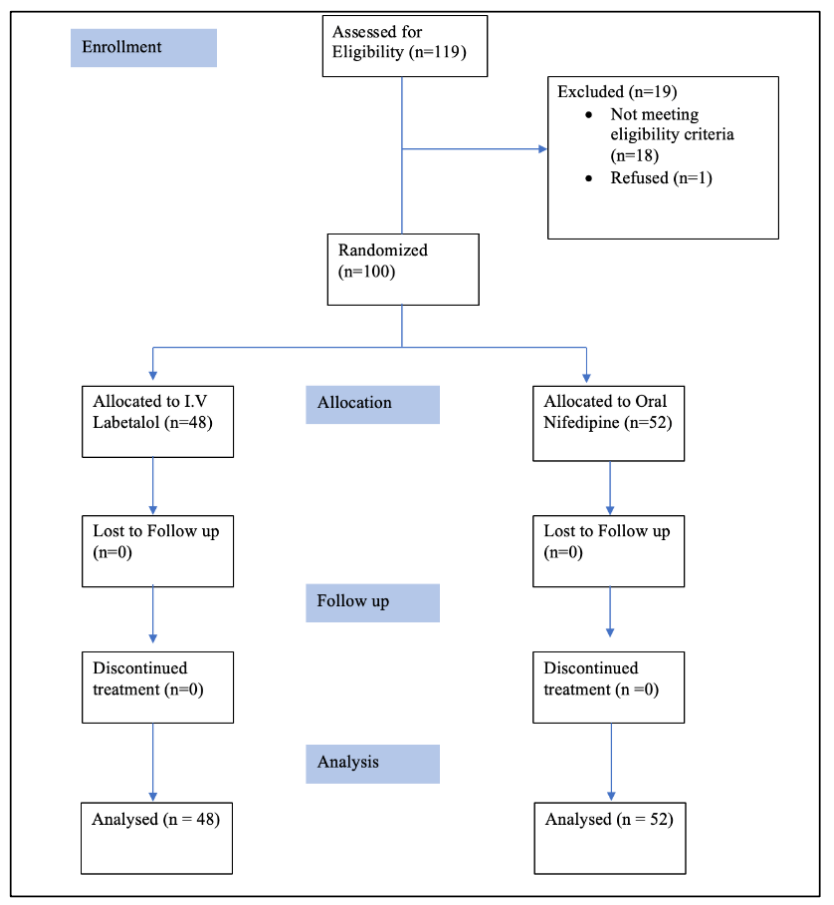

Figure 1. CONSORT flow chart.

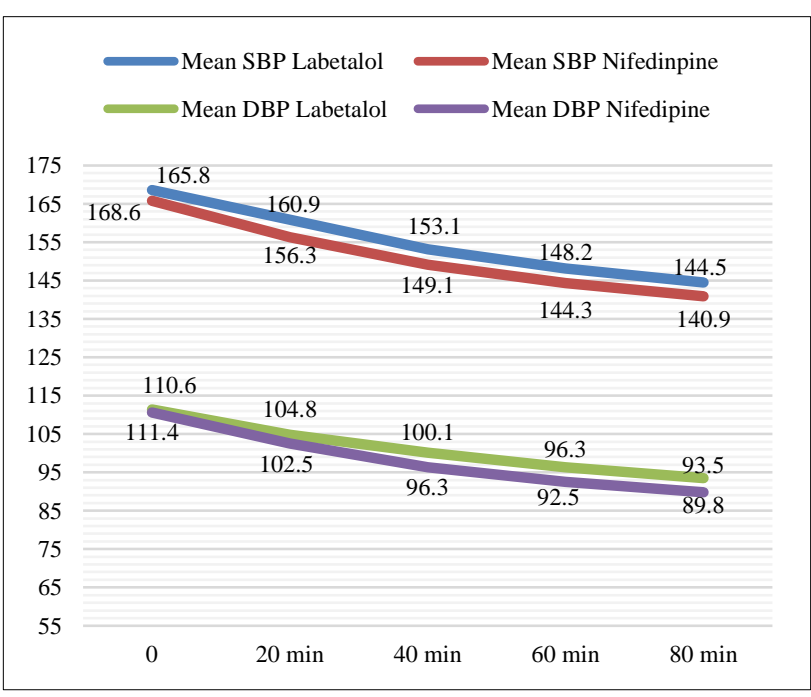

Figure 2: Profiles of mean systolic blood pressure (SBP) and diastolic blood pressure (DBP) during treatment.

Repeated measures analysis of variance of BP for the first 80 minutes indicated that both systolic BP and diastolic BP decreased significantly over time in both groups (Figure 2). The between-group comparison of the nifedipine and labetalol groups showed that both systolic BP and diastolic BP decreased significantly more rapidly in the nifedipine group. The mean maternal heart rate (bpm) at the beginning of treatment was $85 \pm 4.0$ (SD) in the labetalol group and was $85 \pm 3.6$ in the nifedipine group. Repeated measure analysis of variance of maternal heart rate for the first 80 minutes revealed a significant increase till 40 minutes in the nifedipine group and then it did not change significantly.

However, there was no significant difference in the maternal pulse rate in the labetalol group during the first 80 minutes.

Table 1: Baseline characteristics of women in both groups.

\begin{tabular}{|c|c|c|}
\hline Characteristics & $\begin{array}{l}\text { Group I (I.V } \\
\text { labetalol) }\end{array}$ & $\begin{array}{l}\text { Group II } \\
\text { (nfedipine) }\end{array}$ \\
\hline Maternal age (year) & $26.1 \pm 4.4$ & $26.3 \pm 3.9$ \\
\hline Gravid $(1,2,3,4,5)$ & $34,8,4,1,1$ & $30,14,4,1,3$ \\
\hline Parity $(0,1,2,3,4)$ & $37,8,2,1$ & $35,11,4,1,1$ \\
\hline BMI & $24.1 \pm 1.9$ & $24.0 \pm 1.7$ \\
\hline $\begin{array}{l}\text { Period of gestation } \\
\text { (week) at enrollment }\end{array}$ & $37.3 \pm 2.2$ & $37.9 \pm 2.2$ \\
\hline $\begin{array}{l}\text { Period of gestation } \\
\text { (week) at delivery }\end{array}$ & $37.4 \pm 2.3$ & $38.2 \pm 2.1$ \\
\hline $\begin{array}{l}\text { Systolic BP at } \\
\text { enrollment }(\mathrm{mmHg})\end{array}$ & $168.6 \pm 10.0$ & $166.1 \pm 8.3$ \\
\hline $\begin{array}{l}\text { Diastolic BP at } \\
\text { Enrollment (mmHg) }\end{array}$ & $111.46 \pm 6.1$ & $110.65 \pm 6.7$ \\
\hline $\begin{array}{l}\text { Fetal Heart Rate at } \\
\text { enrollment (bpm) }\end{array}$ & $140 \pm 4.6$ & $139 \pm 5.2$ \\
\hline $\begin{array}{l}\text { Pulse rate at } \\
\text { enrollment (bpm) }\end{array}$ & $85 \pm 4.0$ & $85 \pm 3.6$ \\
\hline Proteinuria & $38(79 \%)$ & $42(80 \%)$ \\
\hline $\begin{array}{l}\text { Systolic BP } \geq 160 \\
\mathrm{mmHg}\end{array}$ & $44(91.7 \%)$ & $49(94.2 \%)$ \\
\hline $\begin{array}{l}\text { Diastolic } \mathrm{BP} \geq 110 \\
\mathrm{mmHg}\end{array}$ & $43(89.6 \%)$ & $45(86.5 \%)$ \\
\hline $\begin{array}{l}\text { Magnesium sulphate } \\
\text { use }\end{array}$ & $46(87 \%)$ & $42(88 \%)$ \\
\hline
\end{tabular}

BP: blood pressure, bpm: beats per minute, Data are mean \pm standard deviation, $\mathrm{n}(\%)$, or $\mathrm{n}$ unless otherwise specified, all $\mathrm{p}$ values are $>0.05$.

Table 2: Outcomes of randomized trial comparing oral nifedipine with intravenous labetalol for acute blood pressure control in pregnancy.

\begin{tabular}{|ll|ll|}
\hline & $\begin{array}{l}\text { Group 1 } \\
\text { (labetalol) }\end{array}$ & $\begin{array}{l}\text { Group 2 } \\
\text { (nifedipine) }\end{array}$ & $\begin{array}{l}\text { p } \\
\text { value }\end{array}$ \\
\hline Time required & $52.0 \pm 27.95$ & $37.6 \pm 23.3$ & 0.006 \\
\hline $\begin{array}{l}\text { No of doses } \\
\text { required }\end{array}$ & $2.6 \pm 1.2$ & $1.8 \pm 1.1$ & 0.005 \\
\hline Failure rate & $2(4.1 \%)$ & $1(1.9 \%)$ & \\
\hline $\begin{array}{l}\text { Commonly reported } \\
\text { maternal side } \\
\text { effects }\end{array}$ & $4(8.2 \%)$ & $5(9.5 \%)$ & \\
\hline \begin{tabular}{llll} 
Caesarean sections \\
\hline
\end{tabular} & $19(39.6 \%)$ & $18(34.6 \%)$ & \\
\hline
\end{tabular}




\section{DISCUSSION}

This is one of the few direct comparisons of oral nifedipine and intravenous labetalol in the setting of a randomized clinical trial. The women in nifedipine group took significantly less time and doses than intravenous labetalol to achieve the safe target blood pressures. Ability to achieve lower blood pressure by few tens of minutes might not be clinically important, however this does establish the efficacy of nifedipine as an antihypertensive drug in the setting of severe hypertension during pregnancy. These findings are in keeping with the findings of previous trials. ${ }^{8-10}$ Differences in time taken to achieve target BP across different studies might be explained by variations in frequency and dosing of drugs used as well as by heterogenous definitions of target blood pressure. The use of magnesium sulphate was higher in this study. In this study diagnosis of pre-eclampsia was not always based upon 24-hour urine protein estimation due to time constraints. Spot urine dipstick was used as spot urine protein creatinine ratio was not available. This might have overestimated the incidence of pre-eclampsia and hence higher rates of magnesium sulphate usage. Though the trial lacked power to assess comparative safety of nifedipine, nonetheless absence of any drug related serious side effects in present study, such as overshoot hypotension and maternal tachycardia is reassuring. Reported side effects were also infrequent in both groups. The concerns of refractory hypotension and uterine atony with concomitant use of nifedipine and magnesium sulphate have been convincingly refuted by earlier studies, trials and meta-analysis..$^{5,8,11}$ There was no such incident in the present study despite a high contemporaneous use of magnesium sulphate and nifedipine. Moreover, the effective antihypertensive dose of nifedipine is comparatively less than the tocolytic dose as established in various trial including the present one. ${ }^{8-}$ 10 The main limitation of this trial is that it was an open label trial. Authors could not do masking because of logistical difficulties and it can be a potential cause of assessment bias.

In the present study authors observed very good overall maternal outcomes independent of the drug used. There were no serious adverse events such as pulmonary edema, cerebrovascular accidents, intensive care admissions or maternal mortality. In the setting of a clinical trial, there is a constant reminder to the care providers to adhere to the trial protocols. Hence reassessments are timely and accurate which leads to adequate interventions until the safe target values of a parameter are achieved.

This trial provides additional evidence of safety and effectiveness of nifedipine when used for treatment of severe hypertension during pregnancy. The advantage of simple dosing, low cost and wider availability of nifedipine could be a game changer in low income countries where resources are meagre for using costly intravenous drugs of similar efficacy and safety.

\section{ACKNOWLEDGMENTS}

Authors would like to thank labour room staff, resident doctors and other helping personnel who helped during the course of this study. Authors would also like to thank the patients who agreed to participate in this trial.

\section{Funding: No funding sources \\ Conflict of interest: None declared \\ Ethical approval: The study was approved by the Institutional Ethics Committee}

\section{REFERENCES}

1. Brown MA, Magee LA, Kenny LC, Karumanchi SA, McCarthy FP, Saito S, et al. The hypertensive disorders of pregnancy: ISSHP classification, diagnosis management recommendations for international practice. Preg Hyper. 2018;13:291-310.

2. Souza JP, Gülmezoglu AM, Vogel J, Carroli G, Lumbiganon P, Qureshi Z, et al. Moving beyond essential interventions for reduction of maternal mortality (the WHO multi-country survey on maternal and newborn health): a cross-sectional study. Lancet Lond Engl. 2013;381(9879):1747-55.

3. Duley L, Henderson-Smart DJ, Meher S. Drugs for treatment of very high blood pressure during pregnancy. The Cochrane Database Syst Rev. 2006;3:CD001449.

4. Anonymous. What treatment did you use in your last case of hypertensive emergency in pregnancy? Quick Poll. Obstet Gynecol. 2013.

5. Shekhar S, Gupta N, Kirubakaran R, Pareek P. Oral nifedipine versus intravenous labetalol for severe hypertension during pregnancy: a systematic review and meta-analysis. Int $\mathrm{J}$ Obst Gynaecol. 2016;123(1):40-7.

6. Easterling T, Mundle S, Bracken H, Parvekar S, Mool S, Magee LA, Oral antihypertensive regimens (nifedipine retard, labetalol, and methyldopa) for management of severe hypertension in pregnancy: an open-label, randomised controlled trial. The Lancet. 2019;394(10203):1011-21.

7. Thakur S, Kumari M, Singh K, Shekhar S, Sood A, Sharma R. Perinatal outcome in women with severe hypertension during third trimester of pregnancy treated with intravenous labetalol vs. oral nifedipine: a randomized controlled study. Sub Him J Health Res. 2015;2:64-8.

8. Shekhar S, Sharma C, Thakur S, Verma S. Oral nifedipine or intravenous labetalol for hypertensive emergency in pregnancy: a randomized controlled trial. Obstet Gynecol. 2013;122(5):1057-63.

9. Vermillion ST, Scardo JA, Newman RB, Chauhan SP. A randomized, double-blind trial of oral nifedipine and intravenous labetalol in hypertensive 
emergencies of pregnancy. Am J Obstet Gynecol. 1999;181:858-61.

10. Raheem IA, Saaid R, Omar SZ, Tan PC. Oral nifedipine versus intravenous labetalol for acute blood pressure control in hyper- tensive emergencies of pregnancy: a randomised trial. BJOG. 2012;119:78-85.

11. Magee LA, Miremadi S, Li J, Cheng C, Ensom MH, Carleton B, et al. Therapy with both magnesium sulfate and nifedipine does not increase the risk of serious magnesium related maternal side effects in women with preeclampsia. Am J Obstet Gynecol. 2005;193:153-63.

Cite this article as: Kumari M, Thakur S, Singh K, Shekhar S. Comparative maternal outcomes of oral nifedipine and intravenous labetalol for severe hypertension during pregnancy: an open label randomized controlled trial. Int J Reprod Contracept Obstet Gynecol 2020;9:2847-51. 